\title{
A STUDY OF PERIPHERAL LYMPHADENOPATHY WITH CORRELATION BETWEEN FINE NEEDLE ASPIRATION CYTOLOGY (FNAC) AND BIOPSY IN A TERTIARY CARE HOSPITAL
}

\author{
ISLAM MR ${ }^{1}, \mathrm{HOQUE} \mathrm{MA}{ }^{2}$, EKRAM ARMS ${ }^{3}$
}

\begin{abstract}
:
Background: Lymphadenopathy is a common clinical problem in our country among all age groups and in both sexes. In this study an attempt has been made to evaluate the clinical presentation and diagnosis of peripheral lymphadenopathy, which is commonly encountered in medical wards and diagnostic value of FNAC has been evaluated.

Methodology: This hospital-based descriptive study was done in thirty adult cases, of clinically apparent peripheral lymphadenopathy of at least more than two weeks of duration. Study was conducted over a period of 6 months from July, 2005 to December, 2005 in inpatients and outpatients of Rajshahi Medical College Hospital. After thorough examination, fine needle aspiration from several accessible enlarged lymph node groups were taken and sent for cytopathological examination and later biopsy of the significantly enlarged lymph node from the same anatomical region was performed and was sent for histopathological examination.

Results: Cytopathological study was successful in correctly identifying $84.6 \%$ of tubercular case, 85.7\% of non-Hodgkin's lymphoma, 66.7\% of Hodgkin's lymphoma, 83.3\% of mitotic nodes and $100 \%$ of reactive nodes. Statistical correlation between aetiology of lymphadenopathy and cytopathological diagnosis with Spearman's rank correlation coefficient revealed a strong positive statistically significant correlation of cytopathology with aetiology, i.e. histopathology. Calculation of sensitivity, specificity, positive predictive value, negative predictive value, likelihood ratio for a positive test result and likelihood ratio for a negative test result confirms the diagnostic value of cytopathology in peripheral lymphadenopathy by demonstrating high values for different aetiology.

Conclusion: The result of this study may not exactly reflect that of similar studies conducted home or abroad, probably due to smaller sample size and limited scope, but its strength remains in the fact that it attempted to address a widely prevalent condition in a practical way.
\end{abstract}

Keywords: Aetiology, Clinical Profile, Cytopathology, Histopathology, Lymphadenopathy, Sensitivity, Specificity.

Received: 13 February 2015

Accepted: 3 March 2015

\section{Introduction:}

Lymphadenopathy as a primary presenting sign is seen by physicians and surgeons alike with remarkable regularity ${ }^{1}$. The body has approximately 600 lymph nodes but only those in submandibular axillary or inguinal regions may normally be palpable in healthy people. ${ }^{2}$ Causes are mainly infection, malignancy, autoimmune, metabolic and drugs. Although enlarged lymph nodes are often the initial or most prominent manifestation of whatever disease is present, obvious diagnosis cannot be confirmed at the initial medical examination in many cases. The physician eventually decide whether the lymphadenopathy is normal finding or one that requires further study, up to and including biopsy ${ }^{3}$. In 1904, Grieg and Gray first attempted to aspirate lymph node in the diagnosis of trypanosomiasisIn 1921, Guthrie first attempted to correlate lymph node

1. Dr. Mohammad Rafiqul Islam, Assistant Professor, Department of Medicine, Dhaka Medical College Hospital. Room no-503, DMCH-2, Dhaka

2. Dr. Md. Azizul Hoque, Associate Professor, Department of Medicine, Rajshahi Meidcal College.

3. Prof. ARM Saifuddin Ekram, Professor of Medicine, Rajshahi Meidcal College.

Address of Correspondence: Dr. Mohammad Rafiqul Islam, Assistant Professor, Department of Medicine , Dhaka Medical College Hospital. Room no-503, DMCH-2. Email: drrafiq73@yahoo.com 
aspiration cytology with various disease process ${ }^{4}$. Fine needle aspiration cytology is increasingly used as a diagnostic tool in clinical practice throughout the world 5 . In this study an attempt has been made to evaluate the clinical presentation and diagnosis of peripheral lymphadenopathy, which is commonly encountered in medical wards and diagnostic value of FNAC has been evaluated assuming the result of histopathology as the gold standard. Comparative results of diagnosis vary at different studies in different countries. Therefore, it was rational to identify the sensitivity and specificity of FNAC in comparison to histopathology which may enable to motivate the patients and doctors to adopt the test which will be time saving, less costly and less injurious to the patient

\section{Methodology}

The study was designed as a hospital-based descriptive study. Thirty cases all aged more than 15 years, of clinically apparent peripheral lymphadenopathy of at least more than two weeks of duration was enrolled after explaining the purpose of the study to them and taking informed written consent. Patients aged more than 70 years or suffering from acute lymphadenitis, leukaemia or other chronic advanced heart, liver, kidney comorbidities and diabetics with advanced complications were excluded from this study. Sampling was purposive and the study was conducted over a period of 6 months from July, 2005 to December, 2005 in inpatients and outpatients of Rajshahi Medical College Hospital.

In a predefined questionnaire, data were recorded about the particulars of the patient and relevant clinical symptoms and physical signs. Initially, after adequate explanation and taking consent, fine needle aspiration from several accessible enlarged lymph node groups were taken with a 22 gauge needle with full aseptic precautions, uniform smears were prepared in situ, fixated with 95\% ethyl alcohol and stained according to modified Papanicolus method and sent for cytopathological examination in the department of pathology of the same institution. Later, biopsy of the significantly enlarged lymph node from the same anatomical region was performed under local anesthesia with the help of surgeons and the excised sample was sent for histopathological examination in the same department.

\section{Results}

Of the 30 cases selected, 18 (60\%) were male and 12 $(40 \%)$ were female. Age ranged from 16 to 70 years (Table-I).

Table I

Case distribution of male and female patients in different age groups

\begin{tabular}{lcccc}
\hline \multirow{2}{*}{$\begin{array}{l}\text { Age group } \\
\text { (in years) }\end{array}$} & \multicolumn{3}{c}{ Sex } \\
\cline { 3 - 5 } & Count & $\begin{array}{c}\text { Male } \\
\text { Column } \\
\text { N \% }\end{array}$ & Count & $\begin{array}{c}\text { Column } \\
\text { N \% }\end{array}$ \\
\hline $16-20$ & 3 & $16.7 \%$ & 1 & $8.3 \%$ \\
$21-30$ & 4 & $22.2 \%$ & 5 & $41.7 \%$ \\
$31-40$ & 3 & $16.7 \%$ & 1 & $8.3 \%$ \\
$41-50$ & 2 & $11.1 \%$ & 1 & $8.3 \%$ \\
$51-60$ & 3 & $16.7 \%$ & 3 & $25.0 \%$ \\
$61-70$ & 3 & $16.7 \%$ & 1 & $8.3 \%$ \\
\hline
\end{tabular}

Distribution of aetiologies of lymphadenopathy by histopathology in different age groups demonstrates that more than two thirds of the patients with tubercular lymphadenopathy (9 of 13, 69.23\%) belonged to the age of 40 years or less. This picture remains similar for lymphomas (7 of $10,70 \%$ are at the age of 40 years or less). However, in cases of lymph node metastases, the situation is diametrically opposite ( 6 of $6,100 \%$ cases are above the age of 40 years). (Fig.-1)

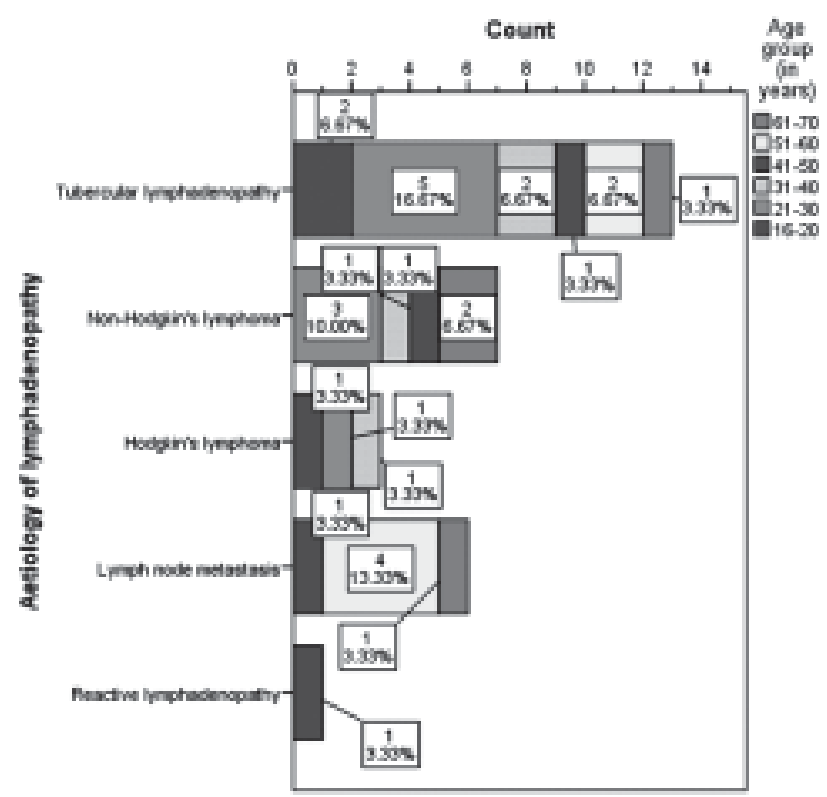

Fig.-1: Graphical presentation of aetiology of lymphadenopathy in different age groups 
Histopathological findings were deemed as gold standard to evaluate diagnostic value of cytopathology in this study. Cytopathological study was successful in correctly identifying $84.6 \%$ of tubercular case, $85.7 \%$ of non-Hodgkin's lymphoma, $66.7 \%$ of Hodgkin's lymphoma, $83.3 \%$ of mitotic nodes and $100 \%$ of reactive nodes. (Table-II)

Commonest clinical symptom was the nodular lymphadenopathy $(30,100 \%)$, which was predictable as it was one of the inclusion criteria. Among other clinical symptoms, anorexia, fever, pain, night sweat and anemia were prevalent in most of the tubercular patients, while weight loss, anorexia and anemia were common in patients with lymph node metastases. Hodgkin's disease presented predominantly with anorexia and fever, while patients with non-Hodgkin's disease mostly suffered from weight loss, fever and night sweat. (Table-III)

Clinical examination findings of the lymphadenopathy revealed characteristic features for different aetiologies. While the tubercular nodes mostly involved single region and were firm, matted, mobile and non-tender. In many cases, mitotic nodes also involved mostly single regions and were hard, discrete, fixed with overlying skin or underlying structure and non-tender. In non-Hodgkin's lymphoma, multiple regional involvements were common as opposed to Hodgkin's disease.Lymph nodes also appeared to be tender in all cases of Hodgkin's disease in contrast to non-Hodgkin's lymphoma. All lymphomatous nodes were firm and mobile. (Table-IV).

The most common anatomical site of involvement of lymph nodes by different diseases was the cervical lymph nodes $(26,86.67 \%)$. (Table V)

Statistical correlation between aetiology of lymphadenopathy and cytopathological diagnosis with Spearman's rank correlation coefficient revealed a strong positive statistically significant correlation of cytopathology with aetiology, i.e. histopathology. (Table -VI).

Calculation of sensitivity (proportion of true positives that are correctly identified by the test), specificity (proportion of true negatives that are correctly identified by the test), positive predictive value (proportion of patients with positive test results who are correctly diagnosed), negative predictive value (proportion of patients with negative test results who are correctly diagnosed), likelihood ratio for a positive test result (how much the odds of the disease increase when a test is positive) and likelihood ratio for a negative test result (how much the odds of the disease decrease when a test is negative) confirms the diagnostic value of cytopathology in peripheral lymphadenopathy by demonstrating high values for different aetiology. (Table VII).

Table -II

Frequency distribution of cytopathological (FNAC) findings in different aetiologies of lymphadenopathy.

\begin{tabular}{|c|c|c|c|c|c|c|c|c|c|c|}
\hline \multirow{3}{*}{$\begin{array}{l}\text { Aetiology of } \\
\text { lymphadenopathy }\end{array}$} & \multicolumn{10}{|c|}{ Cytopathological diagnosis } \\
\hline & \multicolumn{2}{|c|}{$\begin{array}{c}\text { Tubercular } \\
\text { lymphadenopathy }\end{array}$} & \multicolumn{2}{|c|}{$\begin{array}{l}\text { Non-Hodgkin's } \\
\text { lymphoma }\end{array}$} & \multicolumn{2}{|c|}{$\begin{array}{l}\text { Hodgkin's } \\
\text { lymphoma }\end{array}$} & \multicolumn{2}{|c|}{$\begin{array}{l}\text { Lymph node } \\
\text { metastasis }\end{array}$} & \multicolumn{2}{|c|}{$\begin{array}{c}\text { Reactive } \\
\text { lymphadenopathy }\end{array}$} \\
\hline & Count & Row N \% & Count & Row N \% & Count & Row N \% & Count & Row N \% & Count & Row $\mathrm{N} \%$ \\
\hline Tubercular & 11 & $84.6 \%$ & 0 & $0.0 \%$ & 2 & $15.4 \%$ & 0 & $0.0 \%$ & 0 & $0.0 \%$ \\
\hline \multicolumn{11}{|l|}{ lymphadenopathy } \\
\hline \multicolumn{11}{|l|}{$(\mathrm{N}-11)$} \\
\hline Non-Hodgkin's & 0 & $0.0 \%$ & 6 & $85.7 \%$ & 0 & $0.0 \%$ & 0 & $0.0 \%$ & 1 & $14.3 \%$ \\
\hline \multicolumn{11}{|l|}{ lymphoma (N-6) } \\
\hline Hodgkin's & 0 & $0.0 \%$ & 0 & $0.0 \%$ & 2 & $66.7 \%$ & 1 & $33.3 \%$ & 0 & $0.0 \%$ \\
\hline \multicolumn{11}{|l|}{ lymphoma (N-2) } \\
\hline Lymph node & 1 & $16.7 \%$ & 0 & $0.0 \%$ & 0 & $0.0 \%$ & 5 & $83.3 \%$ & 0 & $0.0 \%$ \\
\hline \multicolumn{11}{|l|}{ metastasis $(\mathrm{N}-5)$} \\
\hline Reactive & 0 & $0.0 \%$ & 0 & $0.0 \%$ & 0 & $0.0 \%$ & 0 & $0.0 \%$ & 1 & $100.0 \%$ \\
\hline \multicolumn{11}{|l|}{ lymphadenopathy } \\
\hline$(\mathrm{N}-1)$ & & & & & & & & & & \\
\hline
\end{tabular}


Table-III

Frequency of different clinical symptoms in different aetiologies of lymphadenopathy

\begin{tabular}{|c|c|c|c|c|c|c|c|c|c|c|}
\hline \multirow{3}{*}{$\begin{array}{l}\text { Clinical } \\
\text { features }\end{array}$} & \multicolumn{10}{|c|}{ Aetiology of lymphadenopathy } \\
\hline & \multicolumn{2}{|c|}{$\begin{array}{c}\text { Tubercular } \\
\text { lymphadenopathy }\end{array}$} & \multicolumn{2}{|c|}{$\begin{array}{l}\text { Non-Hodgkin's } \\
\text { lymphoma }\end{array}$} & \multicolumn{2}{|c|}{$\begin{array}{l}\text { Hodgkin's } \\
\text { lymphoma }\end{array}$} & \multicolumn{2}{|c|}{$\begin{array}{l}\text { Lymph node } \\
\text { metastasis }\end{array}$} & \multicolumn{2}{|c|}{$\begin{array}{c}\text { Reactive } \\
\text { lymphadenopathy }\end{array}$} \\
\hline & $\begin{array}{c}\text { Count } \\
\mathrm{N}\end{array}$ & $\begin{array}{l}\text { Column } \\
\%\end{array}$ & $\begin{array}{c}\text { Count } \\
\mathrm{N}\end{array}$ & $\begin{array}{l}\text { Column } \\
\%\end{array}$ & $\begin{array}{c}\text { Count } \\
\mathrm{N}\end{array}$ & $\begin{array}{l}\text { Column } \\
\%\end{array}$ & $\begin{array}{c}\text { Count } \\
\mathrm{N}\end{array}$ & $\begin{array}{c}\text { Column } \\
\%\end{array}$ & $\begin{array}{c}\text { Count } \\
\mathrm{N}\end{array}$ & $\begin{array}{c}\text { Column } \\
\%\end{array}$ \\
\hline Nodular swelling & 13 & $100.0 \%$ & 7 & $100.0 \%$ & 3 & $100.0 \%$ & 6 & $100.0 \%$ & 1 & $100.0 \%$ \\
\hline Fever & 12 & $92.3 \%$ & 6 & $85.7 \%$ & 2 & $66.7 \%$ & 3 & $50.0 \%$ & 0 & $0.0 \%$ \\
\hline Weight loss & 10 & $76.9 \%$ & 7 & $100.0 \%$ & 1 & $33.3 \%$ & 6 & $100.0 \%$ & 0 & $0.0 \%$ \\
\hline Anaemia & 9 & $69.2 \%$ & 4 & $57.1 \%$ & 1 & $33.3 \%$ & 4 & $66.7 \%$ & 0 & $0.0 \%$ \\
\hline Anorexia & 13 & $100.0 \%$ & 3 & $42.9 \%$ & 3 & $100.0 \%$ & 6 & $100.0 \%$ & 0 & $0.0 \%$ \\
\hline Night sweat & 10 & $76.9 \%$ & 6 & $85.7 \%$ & 1 & $33.3 \%$ & 1 & $16.7 \%$ & 0 & $0.0 \%$ \\
\hline Pain & 10 & $76.9 \%$ & 0 & $0.0 \%$ & 1 & $33.3 \%$ & 1 & $16.7 \%$ & 0 & $0.0 \%$ \\
\hline Cough & 4 & $30.8 \%$ & 0 & $0.0 \%$ & 0 & $0.0 \%$ & 1 & $16.7 \%$ & 0 & $0.0 \%$ \\
\hline Voice change & 0 & $0.0 \%$ & 0 & $0.0 \%$ & 0 & $0.0 \%$ & 1 & $16.7 \%$ & 0 & $0.0 \%$ \\
\hline Discharging sinus & 1 & $7.7 \%$ & 0 & $0.0 \%$ & 0 & $0.0 \%$ & 0 & $0.0 \%$ & 0 & $0.0 \%$ \\
\hline Haemoptysis & 2 & $15.4 \%$ & 0 & $0.0 \%$ & 0 & $0.0 \%$ & 1 & $16.7 \%$ & 0 & $0.0 \%$ \\
\hline
\end{tabular}

Table-IV

Frequency of characteristic clinical findings of enlarged lymph nodes in different aetiologies of lymphadenopathy

\begin{tabular}{|c|c|c|c|c|c|c|c|c|c|c|c|}
\hline \multirow{4}{*}{$\begin{array}{l}\text { Clinical characteristics o } \\
\text { lymphadenopathy }\end{array}$} & & \multicolumn{10}{|c|}{ Aetiology of lymphadenopathy } \\
\hline & & \multicolumn{2}{|c|}{$\begin{array}{c}\text { Tubercular } \\
\text { lymphadenopathy }\end{array}$} & \multicolumn{2}{|c|}{$\begin{array}{l}\text { Non-Hodgkin's } \\
\text { lymphoma }\end{array}$} & \multicolumn{2}{|c|}{$\begin{array}{l}\text { Hodgkin's } \\
\text { lymphoma }\end{array}$} & \multicolumn{2}{|c|}{$\begin{array}{l}\text { Lymph node } \\
\text { metastasis }\end{array}$} & \multicolumn{2}{|c|}{$\begin{array}{c}\text { Reactive } \\
\text { lymphadenopathy }\end{array}$} \\
\hline & & Count & Column & Count & Column & Count & Column & Count & Column & Count & Column \\
\hline & & $\mathrm{N}$ & $\%$ & $\mathrm{~N}$ & $\%$ & $\mathrm{~N}$ & $\%$ & $\mathrm{~N}$ & $\%$ & $\mathrm{~N}$ & $\%$ \\
\hline \multirow[t]{2}{*}{ Lymph node region } & Single & 10 & $76.9 \%$ & 1 & $14.3 \%$ & 2 & $66.7 \%$ & 5 & $83.3 \%$ & 1 & $100.0 \%$ \\
\hline & Multiple & 3 & $23.1 \%$ & 6 & $85.7 \%$ & 1 & $33.3 \%$ & 1 & $16.7 \%$ & 0 & $0.0 \%$ \\
\hline \multirow{2}{*}{$\begin{array}{l}\text { Consistency of } \\
\text { enlarged lymph nodes }\end{array}$} & Firm & 13 & $100.0 \%$ & 7 & $100.0 \%$ & 3 & $100.0 \%$ & 0 & $0.0 \%$ & 1 & $100.0 \%$ \\
\hline & Hard & 0 & $0.0 \%$ & 0 & $0.0 \%$ & 0 & $0.0 \%$ & 6 & $100.0 \%$ & 0 & $0.0 \%$ \\
\hline \multirow{2}{*}{$\begin{array}{l}\text { Type of lymph node } \\
\text { enlargement }\end{array}$} & Discrete & 5 & $38.5 \%$ & 7 & $100.0 \%$ & 3 & $100.0 \%$ & 6 & $100.0 \%$ & 1 & $100.0 \%$ \\
\hline & Matted & 8 & $61.5 \%$ & 0 & $0.0 \%$ & 0 & $0.0 \%$ & 0 & $0.0 \%$ & 0 & $0.0 \%$ \\
\hline Fixation of enlarged & Mobile & 11 & $84.6 \%$ & 7 & $100.0 \%$ & 3 & $100.0 \%$ & 2 & $33.3 \%$ & 1 & $100.0 \%$ \\
\hline \multicolumn{12}{|l|}{$\begin{array}{l}\text { overlying skin or } \\
\text { underlying structures }\end{array}$} \\
\hline Tenderness of & Non-tender & 7 & $53.8 \%$ & 7 & $100.0 \%$ & 0 & $0.0 \%$ & 6 & $100.0 \%$ & 0 & $0.0 \%$ \\
\hline enlarged lymph nodes & Tender & 6 & $46.2 \%$ & 0 & $0.0 \%$ & 3 & $100.0 \%$ & 0 & $0.0 \%$ & 1 & $100.0 \%$ \\
\hline Discharging sinus in & Absent & 12 & $92.3 \%$ & 7 & $100.0 \%$ & 3 & $100.0 \%$ & 6 & $100.0 \%$ & 1 & $100.0 \%$ \\
\hline enlarged lymph nodes & Present & 1 & $7.7 \%$ & 0 & $0.0 \%$ & 0 & $0.0 \%$ & 0 & $0.0 \%$ & 0 & $0.0 \%$ \\
\hline
\end{tabular}

Table-V

Distribution of different anatomical groups of lymph nodes as a part of single or multiple regional lymphadenopathies

\begin{tabular}{|c|c|c|c|c|}
\hline \multirow[t]{3}{*}{ Lymph node area } & \multicolumn{4}{|c|}{ Lymph node region } \\
\hline & \multicolumn{2}{|c|}{ Single } & \multicolumn{2}{|c|}{ Multiple } \\
\hline & Count & Column N \% & Count & Column N \% \\
\hline Enlarged submandibular lymph nodes & 0 & $0.0 \%$ & 6 & $54.5 \%$ \\
\hline Enlarged cervical lymph nodes & 16 & $84.2 \%$ & 10 & $90.9 \%$ \\
\hline Enlarged supraclavicular lymph nodes & 2 & $10.5 \%$ & 0 & $0.0 \%$ \\
\hline Enlarged axillary lymph nodes & 1 & $5.3 \%$ & 7 & $63.6 \%$ \\
\hline
\end{tabular}


Table-VI

Correlation of cytopathological diagnosis with histopathological diagnosis

\begin{tabular}{llc}
\hline & Spearman's rho & Histopathological diagnosis \\
\hline Cytopathological diagnosis & Correlation Coefficient & 0.765 \\
& Significance $\left(\mathrm{P}^{*}\right)$ (1-tailed) & 0.000 \\
& $\mathrm{~N}$ & 30 \\
\hline
\end{tabular}

${ }^{*} \mathrm{P}<0.05$ is deemed statistically significant.

Table-VII

Sensitivity, specificity, positive and negative predictive value and likelihood ratio for a positive and negative test result of cytopathological study in different aetiologies of lymphadenopathy

\begin{tabular}{|c|c|c|c|c|c|c|}
\hline $\begin{array}{l}\text { Cytopathological } \\
\text { diagnosis }\end{array}$ & $\begin{array}{l}\text { Sensitivity } \\
\left(\frac{\boldsymbol{T P}}{\boldsymbol{T P}+\boldsymbol{F N}}\right)\end{array}$ & $\begin{array}{l}\text { Specificity } \\
\left(\frac{\boldsymbol{T P}}{\boldsymbol{T P}+\boldsymbol{F N}}\right)\end{array}$ & $\begin{array}{c}\text { Positive } \\
\text { predictive } \\
\text { value } \\
\left(\frac{\boldsymbol{T P}}{\boldsymbol{T P}+\boldsymbol{F N}}\right)\end{array}$ & $\begin{array}{l}\text { Negative } \\
\text { predictive } \\
\text { value } \\
\left(\frac{\boldsymbol{T P}}{\boldsymbol{T P}+\boldsymbol{F N}}\right)\end{array}$ & $\begin{array}{l}\text { Likelihood ratio } \\
\text { for a positive } \\
\text { test result } \\
\left(\frac{\text { Sensitivity }}{1-\text { Specificity }}\right)\end{array}$ & $\begin{array}{l}\text { Likelihood ratio } \\
\text { for a negative } \\
\text { test result } \\
\left(\frac{\text { Sensitivity }}{1-\text { Specificity }}\right)\end{array}$ \\
\hline Tubercular lymphadenopathy & $84.62 \%$ & $94.12 \%$ & $91.67 \%$ & $88.89 \%$ & 14.3912 & 0.1634 \\
\hline Non-Hodgkin's lymphoma & $85.71 \%$ & $100 \%$ & $100 \%$ & $95.83 \%$ & 0.9523 & 1.429 \\
\hline Hodgkin's lymphoma & $66.67 \%$ & $92.59 \%$ & $50 \%$ & $96.15 \%$ & 8.9973 & 0.3600 \\
\hline Lymph node metastasis & $83.33 \%$ & $95.83 \%$ & $83.3 \%$ & $95.83 \%$ & 19.9832 & 0.1740 \\
\hline Reactive lymphadenopathy & $100 \%$ & $96.55 \%$ & $50 \%$ & $100 \%$ & 2.8986 & 0.9322 \\
\hline
\end{tabular}

\section{Discussion}

Symptoms and signs though indicative of diseases are no longer substitute for a morphological diagnosis. Excision of enlarged lymph nodes for histopathological examination has been the final answer for diagnosis until recently.

In this study, tuberculosis was the commonest cause of lymphadenopathy $(13,43.33 \%)$. This was reflected in other studies in the subcontinent where the prevalence of tubercular lymphadenopathy varied from $37 \%$ to $50.9 \%$ 6-9. Observation of higher prevalence of tuberculosis in relatively younger age group is also demonstrated in other studies ${ }^{9,10}$.

The diagnostic sensitivity and specificity of tubercular lymphadenopathy by cytopathology was $84.62 \%$ and $94.12 \%$ in this research. In other studies, the diagnostic accuracy for tubercular cytopathology in different centers varied from $79 \%$ to $98.9 \% .9,11,12$.

7 (23.33\%) of our cases turned out to be non-Hodgkin's lymphoma and 3 (10\%) were Hodgkin's lymphoma. In some other studies conducted on Bangladeshi population, about $57.14 \%$ to $60 \%$ were non-Hodgkin's lymphoma and 40 to $42.86 \%$ were Hodgkin's lymphoma. ${ }^{8-10 .}$

The diagnostic sensitivity and specificity by cytopathology was $85.71 \%$ and $100 \%$ respectively for
non-Hogkin's lymphoma and $66.67 \%$ and $92.59 \%$ respectively for Hodgkin's lymphoma in the present study. Another study in Bangladeshi context found the sensitivity for both about $81 \%$ but specificity of about $75 \%$ and $100 \%$ for non-Hogkin's lymphoma and Hogkin's lymphoma respectively ${ }^{11}$. In a foreign study, sensitivity for both was about $89.6 \%$ and specificity was about $88.5 \%$ and $76.9 \%$ for non-Hogkin's lymphoma and Hogkin's lymphoma respectively ${ }^{12}$.

In this study, one case was diagnosed false negatively as reactive (non-specific) lymphadenitis, which was subsequently confirmed to be a case of non-Hodgkin's lymphoma. The diagnostic accuracy of lymphomas definitely depends on the size of the enlarged lymph node and duration of lymphadenopathy. Lymphoma may start one plane and FNA may miss that particular area $^{12}$. Recent works have demonstrated that the use of immunocytochemistry will increase the accuracy of cytopathological diagnosis of lymphoma and virtually eliminate false positive diagnosis. When those investigators included flow cytometry in conjunction with immunocytochemistry, they found uniform agreement between cytological and histologic sub-classification of lymphoma except for the ability to distinguish the nodular from diffuse subtype of lymphoma ${ }^{8}$. 
Our findings of predominance of mitotic disease in older age group was confirmed in other studies with varying frequency ${ }^{12-14}$.

Diagnostic sensitivity and specificity of cytopathology was calculated to be $83.33 \%$ and $95.83 \%$ for secondary metastases in lymph nodes. In other studies, sensitivity ranged from $80 \%$ to $100 \% 12,13$.

Cytopathological study identified two cases of reactive hyperplasia $(6.67 \%)$ in our study, although it turned out to be only one (3.33\%). Reactive hyperplasia constitutes $9 \%$ to $12.5 \%$ in some other study samples ${ }^{8,12}$. Cytopathology was $100 \%$ sensitive and $96.55 \%$ specific in identifying reactive changes in nodes, although it appears from literature that this diagnosis is somewhat problematic as it presents a polymorphic population of cells showing lymphocyte of varying degree of maturation along with plasma cells and histiocytes.

\section{Conclusion}

Lymphadenopathy is a feature of many diseases presented to different categories of clinicians in everyday practice. Diagnostic dilemma often delays management of the patient. In an endeavor to find out the aetiologic pattern, certain guidelines were set in this study where case history was correlated with the clinic-pathological features, so that clinician may find out the strategy or approach and finalize the diagnosis within shortest time possible. The result of this study may not exactly reflect that of similar studies conducted home or abroad, probably due to smaller sample size and limited scope, but its strength remains in the fact that it attempted to address a widely prevalent condition in a practical way.

\section{References:}

1. Gupta AK, Nayar M, Chandra M. Reliability at limitation of fine Needle Anpirationcytoloqv of Lymphadenopathies. Acts cytol.1991; 35:777.

2. Ferrer R. Lymphadenopathy: Differential diagnosis and evaluation. Am Fam Physician 1998; 58(6): 1313.
3. Henry PH, Lango DL. Enlargement of Iymph nodes spleen. In: Kasper DL, Braunwald E, Fauci AS, Hauser SL, Lango DL, Jameson JL, editor: Harrison's Principles of Internal Medicine. 16th ed. New York. McGraw -Hill; 2005. 343-4

4. Guthrie CC. Gland punctures as a diagnostic measure. BUL Johns Hopkins Hosp. 1901; 82:262-9.

5. Koss LG. wayke S, Otszewski W. Aspiration biopsy cytologic in interpretation and histologic bases. New York: Igckushoin 1984:105-53.

6. Islam A. Clinico-pathological study of peripheral lymphadenopathy in children (dissertation). Dhaka, Bangladesh: Bangladesh College of Physician and Surgeons. 1986; 57-58.

7. Chowdhury HR. Cervical lymphadenopathy: A Chinico-pathological study (Dissertation), Dhaka. Bangladesh College of Physician and Surgeons 1981; 73-74.

8. Gupta AK, Nayar M. Chandra M. Critical appraisal of time needle aspiration cytology in tuberculous lymphadenitis. Actacytol1992: 36391-4.

9. Abdullah P. Mubarik A, Zahir N. The importance of lymph node biopsy in diagnosis of lymphadenopathy. J. Coil physicianssurgpak 2000; 10(8):298-301.

10. Nataraj G, KurupS, Padit A, Mehta P. Correlation of fine needle aspiration cyto9logy and culture in tuberculous lymphadentitis: a propective study. J postgradMed 2002: 48:113-6.

11. Sayeed MA, Sultana R. Zafrullah M, islam MS. Comparative study of FNAC and hitoathologyinthe diagnosis of superficial lymphadenopathy. Bangladesh Med J 2000; 33(1): 3-7.

12. AlAiwan NA, Alhashimi AS, Salman MM, Alattar EA. Fine needle aspiration cytology versus histopathology in diagnosis of lymph node lesion. East Mediterr Health J 1996; 2(2):320-325.

13. Mostofa MG, Fine neele aspiration cytology in clinically significant lymphadenopathy. Chest Heart Bull 1993; 17:43-49.

14. Galib MR. Choddhury MHR, HaqueMs, Anwar MM, Ahsan S. Cervical lymphadenopathy: A study of hundred and twenty cases. Sri Salimulah Med Coll J 2005;13(2):59-63. 